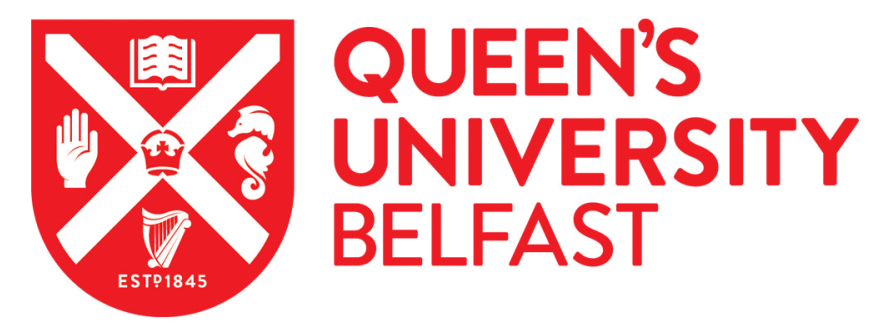

\title{
Are People Changing Address Less? An Analysis of Migration within England and Wales, 1971-2011, by Distance of Move
}

Champion, T., \& Shuttleworth, I. (2016). Are People Changing Address Less? An Analysis of Migration within England and Wales, 1971-2011, by Distance of Move. Population, Space and Place.

https://doi.org/10.1002/psp.2026

Published in:

Population, Space and Place

Document Version:

Peer reviewed version

Queen's University Belfast - Research Portal:

Link to publication record in Queen's University Belfast Research Portal

Publisher rights

Copyright (C) 2016 John Wiley \& Sons, Ltd.

This is the peer reviewed version of this article which has been published in final form at DOI:10.1002/psp.2026. This article may be used for non-commercial purposes in accordance with Wiley Terms and Conditions for Self-Archiving.

\section{General rights}

Copyright for the publications made accessible via the Queen's University Belfast Research Portal is retained by the author(s) and / or other copyright owners and it is a condition of accessing these publications that users recognise and abide by the legal requirements associated with these rights.

Take down policy

The Research Portal is Queen's institutional repository that provides access to Queen's research output. Every effort has been made to ensure that content in the Research Portal does not infringe any person's rights, or applicable UK laws. If you discover content in the Research Portal that you believe breaches copyright or violates any law, please contact openaccess@qub.ac.uk. 


\title{
Are People Changing Address Less? An Analysis of Migration within England and Wales, 1971-2011, by Distance of Move
}

\author{
Tony Champion, Centre for Urban and Regional Development Studies, \\ Newcastle University, Newcastle upon Tyne, UK, and Ian Shuttleworth, \\ School of Geography, Archaeology and Palaeoecology, Queen's \\ University Belfast, Belfast, UK
}

\begin{abstract}
Expectations of migration and mobility steadily increasing in the longer term, which have a long currency in migration theory and related social science, are at odds with the latest US research showing a marked decline in internal migration rates. This paper reports the results of research that investigates whether England and Wales have experienced any similar change in recent decades. Using the Office for National Statistics Longitudinal Study (ONS-LS) of linked census records, it examines the evidence provided by its 10-year migration indicator, with particular attention to a comparison of the first and latest decades available, 1971-1981 and 2001-2011. This suggests that, as in the USA, there has been a marked reduction in the level of shorterdistance (less than $10 \mathrm{~km}$ ) moving that has involved almost all types of people. In contrast to this and to US experience, however, the propensity of people to make longer-distance address changes between decennial censuses has declined much less, largely corroborating the results of a companion study tracking the annual trend in rates of between-area migration since the 1970s (Champion and Shuttleworth, 2016).
\end{abstract}

Keywords: internal migration; migration intensity; long-term trend; ONS Longitudinal Study; England and Wales; microdata

\section{INTRODUCTION}

In recent years the literature on migration and mobilities has been dominated by notions of an increasingly mobile world, such as the world being 'on the move' and now in 'the age of migration' (see, for instance, Cresswell, 2006; Castles and Millar, 2009). Yet it is becoming clear that this is not true of all forms of population mobility or of all parts of the world. In particular, there is now irrefutable evidence that migration rates have been falling in the USA and that this is not just the result of the 2008-09 recession but began considerably earlier. This observation has started to prompt research on the experience of other countries in order to see whether they too have witnessed a similar decline in migration intensities. Little work on trends in migration rates has been undertaken recently for the UK on a comprehensive and long-term basis. As noted below, a study by Lomax et al. (2014) is based on a data set that excludes the vast majority of shorter-distance moves and covers just the single decade 2001-2011, while Champion and Shuttleworth (2016) - in a companion paper to the present one - also deal only with between-area migration, though managing to extend the time frame back to the 1970s. 
The present paper reports the results of new research based on the Office for National Statistics Longitudinal Study of England and Wales (ONS-LS). This is an anonymised microdata set covering a roughly one per cent sample of the population at each census and giving the location of their usual residence at the beginning and end of each intercensal period, thereby permitting the investigation of whether there has been any significant change between decades in the intensity of address changing. Its primary ingredients are a '10-year migration indicator' for each of the four intercensal periods from 1971-1981 through to 2001-2011 and the calculated distance between the recorded addresses at the start and end of each period for those sample members whom this indicator flags up. These two variables allow the tracking of the rates of address changing both in aggregate and for a selection of population subgroups that can be defined consistently across the five censuses involved.

The answer to the question in the paper's title has substantial implications in both theoretical and applied arenas. As regards the former, if a decline in home moving has taken place, it would to some extent challenge the prevailing notion of an ever more mobile society, though it could also be the case that home moving is being substituted by other forms of mobility, as predicted in one of the classic models of migration theory (see below). If no decline is evident, then the question alters to why the UK has not been following the path of the USA in the way that it has done in some other aspects of socio-demographic change. As regards policy, a change in home-moving rates can have both positive and negative connotations, most notably for national prosperity which is normally seen to gain from labour mobility but also at the individual level where greater local rootedness is usually seen as beneficial for social capital and community cohesion.

The rest of the paper is arranged in four sections. The first sets out the background to and the case for the present study. The second justifies the choice of data source and approach, describing the key advantages as well as some limitations of the ONS-LS. Thirdly, the presentation of the descriptive results begins with the overall proportion of people who were living at an address at the end of each intercensal period that was different from that at the start, both in aggregate and by distance-of-move bands, and then goes on to examine the extent to which rates and trends varied between types of people. We conclude with a discussion of the implications of the results. Key issues include how consistent any reduction in migration intensity is with increases in other forms of mobility and whether a long-term decline has the same negative connotations as the temporary falls in migration rates associated with economic recessions.

\section{BACKGROUND}

Much social theory assumes that migration and mobility will increase over the long term because of social and economic change. Common discourses point to 'modernity', 'dislocation' and 'hypermobility' eroding attachment to place and, indeed, eroding the very concept of 'place' and substituting the themes of 'flows' and 'networks'. Theories of a 'liquid modernity' (Bauman, 2000) are associated with postnational 'deterritorialisation' processes and the end of states as containers for societies, helping us to understand why we now live in 'the age of migration' (Castles and Millar, 2009). Globalisation theory also identifies mobility, migration and related population flows as being central to the constitution of the global (Robins, 2000). 
Furthermore, occupational trends in western societies might be assumed to be raising migration rates because the composition of the labour market has been shifting away from blue-collar manual work and becoming increasingly skewed towards higherskilled 'service class' groups with a long tradition of greater geographical mobility (Green, 1992; Fielding, 2012).

These, and similar, ideas have a long currency in migration theory and related social science. Most notably, the notion of increasing population movement was highlighted by Lee (1966) in his refinement of Ravenstein's nineteenth-century 'laws of migration': 'Unless severe checks are imposed, both volume and rate of migration tend to increase with time' (Lee, 1966, p.53). Zelinsky (1971) also drew on the idea in his 'hypothesis of the mobility transition', designed to sit alongside the demographic or, in his terminology, the 'vital' transition and its two components of the epidemiological and fertility transitions. His model delineates the shift from the situation of 'little genuine residential migration' characteristic of pre-modern traditional society through the early and late transitional phases to the advanced society. In the latter, 'For the individual migrant, ... one can postulate a lifetime cycle of residential shifts, along with an elaborate schedule of circulatory trips' (Zelinsky, 1971, pp. 245-246). This is 'a state in which the term "sedentary" no longer seems apposite' and people 'frequently migrate in the sense of formal change of residence', with an annual rate of 20 per cent being quoted for the US population then (p.247).

Such ideas have underpinned the rise of the New Mobilities Paradigm. Cresswell (2006, p.15) notes the centrality of mobility within modernity, quoting from Florence Luscomb's 1911 journal: the 'modern individual is, above all else, a mobile being' According to Sheller and Urry (2006, p.207), 'All the world seems to be on the move'. In the words of Hannam et al. (2006, p.2), 'The global order is increasingly criss-crossed by tourists, workers, terrorists, students, migrants, asylum-seekers, scientists/ scholars, family members, business people, soldiers, guest workers and so on. Such multiple and intersecting mobilities seem to produce a more "networked" patterning of economic and social life...'.

Against this background, it is perhaps not so surprising that commentators seem to have found it difficult to acknowledge that migration rates are not increasing in some parts of the world and to accept that they have been undergoing a secular decline for some considerable time, most notably in the USA. A picture of rapidly declining migration rates in the USA was particularly strongly highlighted by Cooke's (2011) analysis of the 1999-2009 change in inter-state and inter-county migration with much emphasis then being put on the depressing effect of the Great Recession of 2008-09. When it was subsequently recognised that this decadal fall in rates had been exaggerated by time-series data inconsistencies relating to 1999-2005 (Cooke, 2013; Kaplan and Schulhofer-Wohl, 2012), the main impact on the academic debate was to reinforce previous observations that US migration rates had peaked in the 1980s and that some signs of a long-term downturn could be traced back another quarter of a century. In particular, Long (1988) and Gober (1993) both identified an almost uniformly downward trend on overall residential mobility dating back to the early 1950s. Fischer (2002) even traces the phenomenon back into the nineteenth century, concluding that 'Americans today move less often that did their ancestors' (p. 193) and prompting his paper title 'Ever-more rooted Americans'. Small wonder, therefore, that there was more than a hint of frustration in Wolf and Longino's 2005 paper 'Our 
“increasingly mobile society”? The curious persistence of a false belief'! A decade on from Wolf and Longino's (2005) lament, however, it is difficult to believe that anyone could still be labouring under this misapprehension, even if researchers and commentators are primarily drawn from and live among those groups for whom hyper-mobility remains the norm for their work and careers. Moreover, these studies make it clear that decline in migration rates has been occurring at all spatial scales: it has been just as strong for inter-state migration as it has been for between-county within-state moves and within-county address changes.

The sharp decline in US internal migration rates since the mid-1980s prompts the question as to whether any other countries have experienced a similar reduction over the past 30 years. Bell and Charles-Edwards (2013) found declining migration intensities for three of the other five more developed countries for which they had obtained five-year migration data from the 1990 and 2000 census rounds, these being Australia, Canada and Switzerland, with the exceptions being Greece and Portugal. The latest research on the UK (Lomax et al., 2014; Champion and Shuttleworth, 2016) suggests that, while migration rates dropped during the 2008-09 recession, there has been no long-term reduction on anything like the scale observed for the USA. These two studies, however, are based on data sets that record only between-area migration and omit the vast majority of short-distance moves, so there remains the need for a comprehensive analysis that covers all distances of address changing.

\section{THE STUDY: AIM, DATA AND APPROACH}

The primary purpose of this paper is to see whether the intensity of address changing over all distances within England and Wales has been falling in the longer term. Following on from this, the aim is to probe the direct explanations for any such change in terms of how home-moving rates vary between population subgroups. These two research questions require a dataset on address changing that (1) covers all distances of move; (2) spans as long a time period as possible; and (3) contains a range of personal characteristics defined on a consistent basis for this period of time. This section sets out the reasons for choosing the ONS-LS for this study and details its relevant features, including certain limitations that need to be borne in mind when interpreting the results.

The selection of the ONS-LS for this study involved a number of steps. Official surveys were ruled out at an early stage primarily because of sample size, even more so the panel and cohort data sets. The National Health Service Central Register (NHSCR) and the Population Census are the sources that have most commonly been used for monitoring migration trends and patterns since the 1960s (see, for instance, the essays in Stillwell et al., 1992), but both were found to suffer certain weaknesses for present purposes. As documented by Champion and Shuttleworth (2016), the NHSCR can be used to track migration annually from 1971, but it covers only between-area moves and also differentiates people by only age and gender. Meanwhile, the Census collects a wealth of information on people's characteristics including (from 1961) usual address 12 months earlier, with the latter covering all moves irrespective of distance. These enumerations, however, take place only once a decade (apart from the 10\% Census of 1966), with the difference between each year's rate being determined very largely by timing in relation to the business cycle, thus not 
permitting any long-term trend to be identified robustly (Champion and Shuttleworth, 2016).

By comparison with these various sources, the migration data in the ONS-LS was found to be much superior in terms of the criteria set out above. The ONS-LS contains the complete census records of a sample of just over one per cent of the population of England and Wales, starting with the 1971 Census and now incorporating the 2011 Census, with individuals linked between Censuses on an anonymised basis. It includes a variable derived from the usual address of each sample member for which this information is available at each pairing of adjacent censuses, known as the '10-year migration indicator' and in theory covering all distances of move. Moreover, there is a variable giving the straight-line distance between each person's addresses at the start and end of each of these four intercensal decades, where these are different. At the outset this was not available for 1971-1981, but this omission was subsequently rectified (see Acknowledgements). As pointed out by Niedomsyl and Fransson (2014), this precise measure of migration distance is greatly preferable to one based on whether or not a move involves crossing an administrative boundary, given that boundary crossings include a proportion of shorter-distance moves as well as longerdistance ones. This also gives us the opportunity of comparing trends over time for a range of distances of move, which are recognised to differ in terms of their nature and motivation (Gordon, 1982).

At the same time, it is important to be aware of some limitations in the ONS-LS data. One is that, while linkage rates are high (see Lynch et al, 2015), the tracing of ONSLS members between censuses cannot be perfect. Obviously, there can be a valid reason why someone can appear in one census but not the next or vice versa, these being primarily due to births, deaths and migration in and out of the country during the period. For others, though, this may arise from a person being missed off the census return or through different information on name or date of birth being given at the two censuses.

Another limitation is that the range and specific nature of questions asked by the census has altered over time, as some issues rise in salience while others become less important, with the result that it is not possible to get the full benefit of the wealth of information on personal characteristics. Two questions which today are accorded great prominence are ethnicity and health status, but these were first asked only in 1991 and so cannot be included in any systematic analysis that spans the full 19712011 period. Additionally, for some questions that have been asked by all the relevant censuses, there have been changes in the form of the question and/or in the type of answers and the way that they have been categorised in the released variable. For these, it is necessary to collapse the detailed responses into a set of broader categories that are consistent across the censuses.

A more intractable issue is posed by the change in definition of usual residence for students living away from their home during term time, in that for the first time in 2001 this was defined as the term-time rather than the vacation address. Also, there are differences between censuses in the precision with which people's usual address was coded, meaning that there is likely to be slight variation between periods in the coverage of the most localised moves. According to ONS Geography Division (2015), the method was least precise for 1981-1991 (when differences of under 500 metres 
between the Enumeration District centroids were treated as non-moves), while it was most accurate for 1971-1981 (when actual addresses were compared manually) and for 2001-2011 (when addresses were coded to the nearest 1 meter and 0.1 meter at these two censuses respectively) (see also Gleave, 1995; CeLSIUS, 2015). The approach adopted here is to be vigilant in interpreting the findings and, in particular, give less weight to the results for 1981-1991 and focus more on the longer-term changes between 1971-1981 and 2001-2011, while recognising that for the latter period the migration rates are likely somewhat inflated by including some moves of students from and to term-time addresses.

Lastly, there are two drawbacks with the '10-year migration' approach. One is that the time between adjacent censuses is never 10 years to the precise day. While the census has always been held in the spring, its precise timing has varied a little, mainly so as to avoid the Easter weekend which is dictated by the lunar cycle. As the maximum discrepancy is only around 1\% of the decade, it is conventionally ignored in censusbased comparisons of population change between 'decades', and so too it is here. Secondly, the approach picks up only one move per person in an intercensal period, so it cannot identify any additional address changes that might have occurred, and in a similar vein, it will treat someone who has moved away from and back to the same address as a non-mover. Here we follow Bell and Charles-Edwards' (2013) example of not adjusting for multiple moves in their comparison of 5-year migration rates between censuses, mentioned above, but it is an important issue that we return to in the concluding discussion. In sum, there is no data set that is ideal for present purposes: we opt for the best one available.

\section{OVERALL RATES OF 10-YEAR ADDRESS CHANGING}

This section begins by looking at the overall proportion of people who were living at an address at the end of each intercensal period that was different from that at the outset and compare this across the four decades. These are then disaggregated by distance in order to discover whether any change was distributed evenly across all the lengths of move or was more common among longer- or shorter-distance moves.

In the first decade 1971-1981, the number of people who were recorded as usual residents of England and Wales in both censuses and whose birthday fell on one of the four dates eligible for ONS-LS membership was 397,258. Of these, 178,807 were deemed to be living at the same address in 1981 as in 1971, while those with a 10year migration flag numbered 218,451, thus comprising 55.0\% of the total. This might seem a surprisingly low level to those familiar with the level of around 1 in 10 people moving in England and Wales in an average pre-census year, but it is a wellestablished phenomenon arising from the multiple-moves issue just mentioned, dating back at least to Long (1991) and confirmed most recently by Bell et al (2015).

Subsequently, the number of 10-year address changers has declined progressively from its 1970s volume of 218,451 to 214,622, 203,724 and 189,820 for these next three decades respectively, even while total population has risen between each census. As a result, the 10-year migration rate fell steadily across the four decades, reducing to $53.0 \%$ for the 1980 s, $49.8 \%$ for the 1990 s and $45.3 \%$ for the 2000 s, an overall fall of $9.7 \%$ points between the first and last decades and representing a relative decline 
of $17.7 \%$ from the 1970 s rate. Clearly, in answer to the primary question posed for this study, according to this measure of migration intensity the population of England and Wales would appear to have been moving home substantially less in recent years than was the case three decades ago.

The first step in understanding why the 10-year address changing rate has been falling is to disaggregate the overall rate by the distance between people's addresses at the start and end of the decades. Figure 1 displays the rates for four distance-of-move bands. It is immediately apparent that the fall in overall rate is almost entirely the result of reduced short-distance moving, with the proportion changing address by less than $10 \mathrm{~km}$ dropping by $9.4 \%$ points from $36.9 \%$ to $27.5 \%$, a relative decline of almost a quarter (24.5\%). By contrast, the rates for the three longer-distance bands altered only marginally, with the 2001-2011 rate for $200 \mathrm{~km}+$ moves lower than that of $1971-1981$ by just 0.2 points, that for $10-<50 \mathrm{~km}$ down by 0.1 and that for $50-<200 \mathrm{~km}$ unchanged.

\section{Figure 1 about here}

This finding is significant for two reasons. One is that the main change appears to have taken place in the short-distance moves that are largely missed by the NHSCR's data on between-area moves. This would explain why studies based on the latter suggest very little, if any, reduction in migration rates over time, aside from the shortterm fluctuations related to the business cycle. Secondly, the evidence of Figure 1 suggests that the sharp reduction in migration rate associated with the deep recession of 2008-09 observed by Lomax et al (2014) has not significantly reduced the scale of longer-distance migration after 2001 in comparison with the time period back to the 1970s, perhaps not surprisingly given that each of the previous three decades also experienced a mixture of boom and bust conditions.

How much confidence can be placed in these findings, given the two main uncertainties over the data mentioned above? As regards the possibility of the shortest-distance address changing being undercounted in 1981-1991, the only effect of this would be to raise the proportion moving less than $10 \mathrm{~km}$ somewhat beyond the calculated rate of $34.7 \%$, which would also increase the overall migration rate. This would make the profile for 1981-1991 look more like that of the previous decade, but it would not alter the general conclusion that 10-year address changing has generally been declining during our study period, only that perhaps it started somewhat later than suggested by Figure 1. The corollary of this is that the fall in rate, once it had got underway, would be sharper than shown there.

The other main source of concern about the data - that relating to the change in the definition of usual address for students - could also be deemed to accentuate rather than undermine the main finding of address changing rates falling over time. The inclusion of moves to university in 1991-2001 will have artificially swelled the overall rate for that decade somewhat, with the inclusion of moves both to and from university in 2001-2011 doing this even more. If the address changing of the last two decades could have been put on the same basis as the first two, then the decrease in rate across the study period would likely have been even more marked. 
There is therefore no question that 10-year address-changing has decreased over recent decades nor that this is primarily due to shorter-distance moving. The only uncertainty is whether the decline started after the 1970s or the 1980s. In now going on to examine the trend in greater detail, our approach is to focus primarily on how much different the pattern for 2001-2011 is from that of our first decade 1971-1981, i.e. comparing the two decades for which we have the greatest confidence in the quality of the short-distance moving data, but caution still needs to be exercised over the possible swelling of the rates for 2001-2011 arising from the student issue.

\section{VARIATION IN 10-YEAR ADDRESS CHANGING BETWEEN PEOPLE}

This section of the paper has two principal objectives. The first is to become more familiar with the nature of 10-year address changing, given that, as mentioned, this measure is not commonly used in migration studies. In particular, are the types of people who do or do not stay put over a decade-long period the same ones that are less or more residentially mobile according to sources that monitor continuously or provide data on one-year change of address? Secondly and more importantly, the aim is to discover which types of people are the ones most involved in the observed decline in 10-year address changing since the 1970s. In particular, which have seen their propensity to make a move of less than $10 \mathrm{~km}$ drop the most by 2001-2011?

\section{Which People are Most and Least Migratory Over a 10-Year Period?}

This question is tackled using the address changing rates for our first decade 19711981. A wealth of previous studies gives a very clear idea of what to expect. One of the most comprehensive is that of Owen and Green (1992), who drew on a variety of sources on one-year or continuous address changing including the 1981 Census, the Labour Force Survey and Building Society data to portray differentials in migration propensities for the 1980s. They found virtually no difference in rate between males and females, but considerable differences by age (with the 16-34s being most mobile), by occupation (highest for managerial and professional, plus those in personal and protective services), by highest qualification (highest for those with degrees and A Levels) and by housing tenure (much the highest for the private-rented sector). How does this profile of migration intensity compare with that for 10 -year address changing?

To answer this question, the left-hand panel of Table 1 lists in rank order the 15 types of people with the highest rate of address changing over any distance for 1971-1981 out of the full list of types analysed for this study. The characteristic refers to status in 1971, and the importance of age is immediately apparent. All age groups from 10 to 29 (becoming 20-39 by the end of the decade) are included, along with 0-4s who are normally members of families headed by these age cohorts. Linked to age is the appearance in this list of students, singles, private renters and the unemployed.

Members of the armed forces (included in Owen and Green's 'personal and protective services') have the highest rate of all, while the most highly educated and those in professional and skilled white-collar jobs also parallel those identified as most likely to be one-year migrants by Owen and Green, along with people born outside the UK.

Table 1 about here 
Table 1 also lists the types of people with the highest propensity to make the shortest and longest distance address changes between 1971 and 1981. As is recognised in the literature (Coulter and Scott, 2015), the correlates of moving differ by distance (or, more usually, by whether a migrant crosses a regional boundary or not), the more skilled and educated appear high up in the $50 \mathrm{~km}+$ list but not in the $<10 \mathrm{~km}$ one, and vice versa for the less skilled, while military personnel are especially highly mobile over long distance as expected (Gordon 1982; Niedomysl 2011). Higher rates of localscale turnover are also characteristic of social renters and more vulnerable people such as the divorced and unemployed. Younger age groups and associated types like singles and private renters, however, feature strongly among both distances of address changing.

These patterns of differentiation thus accord well with what is known about variations in migration rates measured over periods much shorter than a decade. This suggests that any findings from the ONS-LS about which types of people have seen the greatest decreases in 10-year address changing would very likely also be exhibited by a continuous sequence of data on one-year address changes if such a source covering more than age and gender had been available for this study.

\section{For Which People Has the 10-Year Address-Changing Rate Declined Most?}

This question is answered by calculating the percentage change in 10-year addresschanging rate between 1971-1981 and 2001-2011, with people classified on the basis of their status at the start of the each of the two decades respectively. Table 2 ranks the 15 population types in the analysis in order of greatest decline for each of three distances of move.

Table 2 about here

Looking first at all distances of move (left-hand panel of Table 2), it is evident that the older age groups are a key driver of declining rates: not only did the older age groups generally have the lowest rate at the outset in the 1970s, but they have experienced the largest relative decline in rate since then, getting on for a halving of rate for those aged 65-69 (becoming 75-79 by the end of the decade). The appearance of the retired and widowed in this list merely confirms the importance of age. Self-employment also tends to be more common in the older working-age population. There is also probably an age element in the presence of 'sick' (i.e. economically inactive because of permanent illness) in the list, so too that of the divorced and married, reinforced by the trend towards delayed marriage which will have shifted the composition of these groups towards the less migratory ages. Compositional change may also be the reason for the non-UK-born appearing in this list, given that the rate of immigration slowed between the 1970s and 1990s and thus the non-native population matured into the less migratory ages.

The picture is very similar for the change in the rate of moving less than $10 \mathrm{~km}$ (middle panel of Table 2), not surprisingly given the predominance of shorter-distance moving already seen in Figure 1. Older age is even more emphatically the main driver here, with the rate more than halving for the 65-74s between the 1970s and the 2000s. The pattern is, however, somewhat different for longer-distance migration (see the 
right-hand panel). Older age still features quite strongly in this, but the greatest relative contraction in the proportion of people moving $50 \mathrm{~km}$ or more between censuses is for those holding a degree or equivalent tertiary qualification, down by fully one-third in marked contrast to the overall decline of just $2.6 \%$. This may well be linked to the the appearance in this list of the top two occupational skill groups and of owner-occupiers, all with rates down by a fifth or more.

At the other end of the spectrum (not shown in Table 2), there are two cases where the rate actually rose against the overall trend, namely private renters (up by 7\%) and 2529 year olds (up by $2 \%$ ). As regards the shortest-distance moves (under $10 \mathrm{~km}$ ), again there are two types where the rate actually rose between the 1970s and the 2000s, this time featuring members of the armed forces (with a 4\% increase) as well as 25-29 year olds again (but just by $1 \%$ ). For moves over $50 \mathrm{~km}$, the pattern is considerably different. There are increases for those aged 10-24, private renters, single people and the unskilled.

It is thus apparent that age is the single most important discriminator in trends in the all-moves rate so a closer look is now taken at this, drawing on data for all four decades. Figure 2 confirms that the reductions in 10-year migration rate have been much greater for some age groups than others, with the steepest falls being for those aged 50 and over at the start of each decade. Going further, it also reveals a fairly consistent progression across the four decades. By contrast, there has been virtually no change in moving rate for those aged between 25 and 39. For those in their 40s and the under-20s, the reductions in rate are modest compared to those aged 50 and over.

Figure 2 about here

Finally, in relation to longer-distance migration, it is occupational status that seems to play a key role. As shown in Figure 3, across the four decades there is a broad contrast in the trend in $50 \mathrm{~km}+$ moving rate between the three more highly skilled social/skill groups and the three lower ones. The former have each seen a progressive decline in rate. By contrast, there is a rather flat trajectory for skilled manual workers (Social Class IIIM) and an increase in rate for the partly skilled and unskilled groups (Social Classes IV and V). The result is a considerable convergence in the 50km+ migration rate across these six main groups, with occupational status becoming less of a discriminator by the 2000 s.

Figure 3 about here

\section{CONCLUDING DISCUSSION}

This study of long-term trends in the intensity of address changing was prompted partly by the now well-documented phenomenon of migration decline in the USA (see Cooke, 2011, 2013) but also by the finding in our companion paper to this one (Champion and Shuttleworth, 2016) that, according to the NHSCR's migration data, there has been no substantial fall in overall migration rates in England and Wales since the start of continuous recording in 1971, merely fluctuations largely associated with the business cycle. This paper has reported the results from an alternative data source, namely the ONS-LS with its variable on 10-year migration that helps to even 
out short-term cyclical effects. According to this, migration in England and Wales has declined markedly in recent decades, with the 10-year rate for all moves falling from 55 per cent for 1971-1981 to barely 45 per cent in 2001-11, a percentage decrease of some 18 per cent.

Yet these two sets of findings for England and Wales are not as incompatible as would seem at first glance. This is principally because the data used in the present study covers all distances of address changing whereas the NHSCR data set used in the companion study records only moves between quite large areas and is thus dominated by longer-distance moving. The distance breakdown available in the ONSLS confirms that over the past four decades the overall propensity of people to move longer distances has not declined as much in England and Wales as in the USA. The biggest changes have been restricted to moves of less than $10 \mathrm{~km}$, for which the rate dropped by a quarter between the 1970s and the 2000s according to the ONS-LS data. These are the moves that are largely unrecorded in the NHSCR. However, despite the differences between the two data sets, there is also some consistency in that both show reduction in older people's migration as being a significant element in the lowering of rates over this period.

At the same time, the present study has been able to probe further than its companion by virtue of the ONS-LS containing information on a much wider range of personal characteristics than the NHSCR. For one thing, it is now clear that the decline in overall migration rate is a widespread phenomenon, involving not just older people but shared by virtually all the population subgroups tracked in this study, albeit to varying extents but with only a couple of exceptions, notably those living in the private rented sector. The latter have also been shown to be key to the relative resilience of longer-distance moving, perhaps associated in part with the rising numbers going into higher education. Less expected in terms of the propensity of people to move $50 \mathrm{~km}$ or more over a decade, however, is the apparent convergence of long-distance moving rates across the social scale. This merits further investigation, though one can speculate that the growth of white-collar work at the expense of bluecollar - which in itself is shifting population composition towards the traditionally more mobile groups - is moving less migratory types of people up the official socialclass scale. Similarly, the expansion of higher education means that graduates are now more like the general population than when they were more of a minority in the 1970s.

In sum, the two principal findings of the long-term decline in short-distance moving and the relative resilience of longer-distance migration merit further attention. The fall in local residential mobility since the 1970s is so marked that it is surprising that the present study represents the first systematic attempt to document it. As regards there being evidence of only a small reduction in the propensity to migrate over longer distances, the task is somewhat different, with the emphasis initially needing to be put on the verification of this finding and then, if confirmed, on the investigation of the reasons behind the contrast with US experience.

It is difficult to explain these observations in England and Wales but one can consider how to go about this task. The starting point is the recognition that the act of migration is a function of the desire to move and the structural factors that hinder (or permit or even force) moves. Attempts to deal with motivations are limited by our 
data - the Census, while showing some of the characteristics that are correlated with migration, says nothing about the motivations for migration nor does it tell us anything about people who desire to change address but are frustrated. Far more is known about the individual and household correlates of moves (e.g. Niedomysl 2011) than about the reasons that people state for moving home. Sometimes where motivational information is available it is only for those who have migrated and then often only after the event, whereas it is preferable to know about migration intentions before the event, both for those who later move and also for those who do not (Coulter and Scott, 2015).

The individual desire to move is part of a whole nexus of relationships with other household members, with the local neighbourhood and with broader structural factors such as the housing and labour markets which can help or hinder people in realising their migration plans. Structural factors are a difficult concept, ranging from longwave economic, social and demographic change (e.g. the second demographic transition and the transition from Fordism) to conjunctural forces such as the 2008-09 recession and the vagaries of national social and economic policies (Coulter et al, 2015; Coulter and Scott, 2015; see also Fielding, 2012). It is not easy conceptually to separate individual moving desires from structural and wider social developments since these developments could construct the desire to move or to stay put.

In understanding why migration rates have declined for most types of people in England and Wales since the 1970s, one possible explanation in this framework is that migration intention rates have fallen as a response to structural or other forces. In this variant of Cooke's (2011) 'secular rootedness' argument, it is hypothesized that there has been a real change in the way that people view spatial mobility and migration careers over the life course. Alternatively, migration intention rates have remained constant, but more people have latterly been frustrated by external forces and forced to stay put.

It is difficult to get data on migration intentions over the time period required for this paper, but there is some evidence that permits speculation. In this regard, the study of migration motivations in the 1990s by Coulter and Scott (2015) is especially pertinent. A telling point is that migration desires at Time $\mathrm{T}$ were a good predictor of an actual move by Time $T+1$. This suggests that people who wanted to change address were able to do so and they were not constrained then. Most of these desired moves were found to be associated with housing and neighbourhood and are most commonly linked to older people and local moves. Undesired moves were associated with partnership, education, and employment reasons, the sorts of issues that mainly drive migration for younger people and longer-distance migration. While this evidence is by no means conclusive, it supports the suggestion that declining migration intentions may have played an important part in explaining the decrease in migration rates in England and Wales since the 1970s, as Coulter and Scott (2015) found few 'frustrated movers'. It is also difficult to imagine how a common set of structural constraints on moving might act across all the population groups we observe, given their diversity and their contrasting reasons for moving.

Besides the development of a framework to think through how changes in migration rates, there are also further opportunities for empirical research to understand better why and how national migration rates change. One extension of the research in this 
paper would be to decompose the decline in England and Wales migration rates in order to distinguish the relative contributions of structural change (e.g. population ageing) and changing migration propensities. A second avenue could explore a fuller measure of migration by considering first, second and subsequent moves. There is a possibility that the measure used in this paper exaggerates overall migration decline if the people who are recorded as moving between censuses are becoming more likely to make second and subsequent moves. Censuses can tell us little about this, so recourse is needed to other survey and administrative sources. Yet the number of people making increasingly frequent address changes is likely to be small and insufficient to reverse the trends observed here. Evidence from another part of the UK, Northern Ireland, for example, shows that the majority of address changers in the decade since 2001 made only one move (Shuttleworth et al, 2013). A third avenue for development is to explore age, cohort and period effects by following the migration experiences of different age cohorts forward from 1971 to 2011. This would move the analysis from a consideration of repeated cross-sections to a full longitudinal design, but would limit the degree of comparison over time for specific life stages.

\section{ACKNOWLEDGEMENTS}

Data analyses in this paper are based on micro-data from the Office for National Statistics' (ONS) Longitudinal Study (LS), linking England and Wales Census data for a (roughly) 1\% sample of the population, accessed securely via the Virtual Microdata Laboratory at ONS. Census output is Crown Copyright and is reproduced with the permission of the Controller of HMSO and the Queen's Printer for Scotland. The permission of ONS to use the LS is gratefully acknowledged, as is the help provided by staff at the Centre for Longitudinal Study Information \& User Support (CeLSIUS), notably Christopher Marshall, and the advice of Kevin Lynch at ONS. CeLSIUS is supported by the ESRC Census of Population Programme (Award Ref: ES/K000365/1). The presentation has been cleared by ONS (Clearance Number 401006), but the authors alone are responsible for the interpretation of the data. The authors would also like to thank Paul Norman for his assistance in calculating the 10year migration distances for 1971-81, and Tom Cooke for his advice during the analytical stages of this work. Additionally, the authors are grateful for comments received at the presentation of an earlier version of this paper at the SERC Annual Conference 2014.

\section{REFERENCES}

Bauman Z. 2000. Liquid Modernity. Polity Press: Cambridge.

Bell M, Charles-Edwards E. 2013. Cross-national Comparisons of Internal Migration: An Update on Global Patterns and Trends. Technical Paper No. 2013/1. United Nations Department of Economic and Social Affairs: New York.

Bell M, Charles-Edwards E, Ueffing P, Stillwell J, Kupiszewski M, Kupiszewska D. 2015. Internal migration and development: comparing migration intensities around the world. Population and Development Review 41: 33-58.

Castles S, Millar MJ. 2009. The Age of Migration. Palgrave Macmillan: Basingstoke, $4^{\text {th }}$ edition. 
CeLSIUS. 2015. Migration variables in the LS. http://www.ucl.ac.uk/celsius/onlinetraining/geography/ge060100.

Champion T, Shuttleworth I. 2016. Is internal migration slowing? An analysis of the annual record for England and Wales since the 1970s. Population, Space and Place doi ???

Cooke TJ. 2011. It is not just the economy: declining migration and the rise of secular rootedness. Population, Space and Place 17: 193-203.

Cooke TJ. 2013. Internal migration in decline. The Professional Geographer 65: 664675.

Coulter R, Scott J. 2015. What motivates residential mobility? Re-examining selfreported reasons for desiring and making residential moves. Population, Space and Place 21: 354-371.

Coulter R, Van Ham M, Findlay AM. 2015. Re-thinking residential mobility Linking lives through time and space. Progress in Human Geography, OnlineFirst DOI: 10.1177/0309132515575417.

Cresswell T. 2006. On the Move: Mobility in the Modern Western World. Taylor and Francis: London.

Fielding T. 2012. Migration in Britain. Edward Elgar: Cheltenham.

Fischer CS. 2002. Ever-more rooted Americans. City \& Community 1: 177-198.

Gleave S. 1995. The development of a 1981-1991 migration indicator. In OPCS Longitudinal Study Update 10.

Gober P. 1993. Americans on the move. Population Bulletin, November. Population Reference Bureau: Washington DC.

Gordon IR. 1982. The analysis of motivation-specific migration streams. Environment and Planning A 14: 5-20.

Green A. 1992. Changing labour market processes and internal migration. In Migration Processes and Patterns Volume 1: Research Progress and Prospects, Champion T, Fielding T (eds). Belhaven Press: London; 105-118.

Hannam K, Sheller M, Urry J. 2006. Editorial: Mobilities, immobilities and moorings. Mobilities 1: 1-22.

Kaplan G, Schulhofer-Wohl S. 2012. Interstate migration has fallen less than you think: Consequences of hot desk imputation in the Current Population Survey. Demography 49: 1061-1074.

Lee ES. 1966. A theory of migration. Demography 3: 47-57.

Lomax N, Stillwell J, Norman P, Rees P. 2014. Internal migration in the United Kingdom: analysis of an estimated inter-district time series, 2001-2011. Applied Spatial Analysis and Policy 7: 25-45.

Long L. 1988. Migration and Residential Mobility in the United States. Russell Sage Foundation: New York.

Long L. 1991. Residential mobility differences among developed countries. International Regional Science Review 14: 133-147.

Lynch K, Lieb S, Warren J, Rogers R, Buxton J. 2015. Longitudinal Study 20012011: Completeness of Census Linkage. Series LS No. 7, Office for National Statistics: Titchfield, Hants.

Niedomysl T. 2011. How migration motives change over migration distance: evidence on variation across socio-economic and demographic groups. Regional Studies 45: 843-855.

Niedomsyl T, Fransson U. 2014. On distance and the spatial dimension in the definition of internal migration. Annals of the Association of American Geographers 104: 357-372. 
ONS Geography Division 2015. Personal communication, see also

http://www.ons.gov.uk/ons/guide-method/census/census-2001/data-andproducts/output-geography/geographical-referencing/index.html and http://www.ons.gov.uk/ons/guide-method/census/2011/how-our-censusworks/how-we-planned-the-2011-census/design-for-the-2011-census/compilingthe-address-register/index.html

Owen D, Green A. 1992. Migration patterns and trends. In Migration Processes and Patterns Volume 1: Research Progress and Prospects, Champion T, Fielding T (eds). Belhaven Press: London; 17-38.

Robins K. 2000. Encountering globalization. In The Global Transformation Reader, Held D, McGrew AG (eds). Polity Press: Cambridge.

Shuttleworth I, Barr P, Gould M. 2013. Does internal migration in Northern Ireland increase religious and social segregation? Perspectives from the Northern Ireland Longitudinal Study (NILS), 2001-2007. Population, Space and Place 19: 72-86.

Sheller M, Urry J. 2006. The new mobilities paradigm. Environment and Planning A 38: 80-93.

Stillwell J, Rees P, Boden P (eds). 1992. Migration Processes and Patterns Volume 2: Population Distribution in the United Kingdom. Belhaven Press: London.

Wolf DA, Longino CF. 2005. Our ‘increasingly mobile society’? The curious persistence of a false belief. The Gerontologist 45: 5-11.

Zelinsky W. 1971. The hypothesis of the mobility transition Geographical Review 61: 219-249.

\section{TABLES AND FIGURES}

Table 1. The 15 types of people with the highest rate of 10-year address change 19711981, by distance of move

\begin{tabular}{|l|l|l|l|l|l|l|}
\hline \multirow{2}{*}{ Rank } & All distances of move & \multicolumn{2}{l|}{ Less than 10km } & \multicolumn{2}{l|}{ 50km and over } \\
\cline { 2 - 7 } & Type & $\%$ & Type & & Type & $\%$ \\
\hline & & & & & \\
\hline 1 & Armed forces & 88.2 & $15-19$ & 53.7 & Armed forces & 60.1 \\
\hline 2 & Student aged 15+ & 87.6 & $20-24$ & 51.4 & Student aged 15+ & 33.0 \\
\hline 3 & $15-19$ & 87.3 & Private renter & 45.6 & Degree & 19.0 \\
\hline 4 & $20-24$ & 84.3 & $10-14$ & 44.7 & Professional & 16.6 \\
\hline 5 & Private renter & 71.5 & $25-29$ & 43.3 & $15-19$ & 16.4 \\
\hline 6 & $25-29$ & 70.3 & Divorced & 43.2 & $20-24$ & 15.3 \\
\hline 7 & $10-14$ & 68.0 & Single & 42.7 & Intermediate & 13.9 \\
\hline 8 & Single & 65.6 & Unemployed & 42.4 & Private renter & 13.7 \\
\hline 9 & Divorced & 63.1 & $0-4$ & 42.3 & $25-29$ & 13.1 \\
\hline 10 & Unemployed & 62.6 & Social renter & 41.6 & $10-14$ & 12.2 \\
\hline 11 & $0-4$ & 62.3 & Non UK Born & 41.0 & Single & 11.6 \\
\hline 12 & Non UK born & 61.2 & Unskilled & 40.1 & Skilled non-manual & 11.1 \\
\hline 13 & Skilled non-manual & 58.7 & $30-34$ & 38.2 & $85+$ & 11.0 \\
\hline 14 & Degree & 58.5 & Skilled manual & 38.1 & Non UK born & 11.0 \\
\hline 15 & Professional & 58.2 & Partly skilled & 37.2 & Owner occupier & 10.6 \\
\hline
\end{tabular}

Note: Degree includes other tertiary qualifications. Intermediate refers to Social Class II.

Source: Calculated from ONS-LS. Crown Copyright. 
Table 2. The 15 types of people with the greatest relative decrease in their 10-year address-change rate between 1971-1981 and 2001-2011, by distance of move

\begin{tabular}{|l|l|l|l|l|l|l|}
\hline \multirow{2}{*}{ Rank } & All distances & Less than 10km & \multicolumn{2}{l|}{$50 \mathrm{~km}$ and over } \\
\cline { 2 - 7 } & Type & $\%$ & Type & $\%$ & Type & $\%$ \\
\hline & & & & & & \\
\hline 1 & Retired & -44.7 & $65-69$ & -53.6 & Degree & -33.6 \\
\hline 2 & $65-69$ & -44.6 & Retired & -53.0 & $85+$ & -31.7 \\
\hline 3 & $70-74$ & -43.5 & $70-74$ & -50.7 & $0-4$ & -29.9 \\
\hline 4 & $60-64$ & -40.0 & $60-64$ & -47.2 & $60-64$ & -29.6 \\
\hline 5 & $75-79$ & -37.8 & $55-59$ & -43.7 & Intermediate & -28.8 \\
\hline 6 & Widowed & -34.7 & Widowed & -43.2 & $70-74$ & -27.5 \\
\hline 7 & $55-59$ & -33.0 & $75-79$ & -42.0 & Divorced & -27.4 \\
\hline 8 & Non UK born & -31.4 & $80-84$ & -39.3 & Armed forces & -26.2 \\
\hline 9 & Divorced & -31.1 & $50-54$ & -38.4 & Married & -25.4 \\
\hline 10 & Married & -30.7 & Non UK born & -36.5 & $65-69$ & -25.3 \\
\hline 11 & $80-84$ & -29.6 & Divorced & -36.0 & Retired & -24.8 \\
\hline 12 & Sick & -27.4 & Unskilled & -35.9 & Professional & -23.6 \\
\hline 13 & Unskilled & -25.8 & Married & -35.3 & Non UK born & -22.6 \\
\hline 14 & $50-54$ & -25.7 & Sick & -32.3 & Employed part-time & -21.3 \\
\hline 15 & Self-employed & -23.9 & $45-49$ & -30.2 & Owner occupier & -21.1 \\
\hline
\end{tabular}

Note: Degree includes other tertiary qualifications. Intermediate refers to Social Class II.

Source: Calculated from ONS-LS. Crown Copyright.

Figure 1. Proportion of the starting populations with a different address at the end of the decade from that at the start by distance of move (Source: calculated from ONSLS. Crown Copyright.)

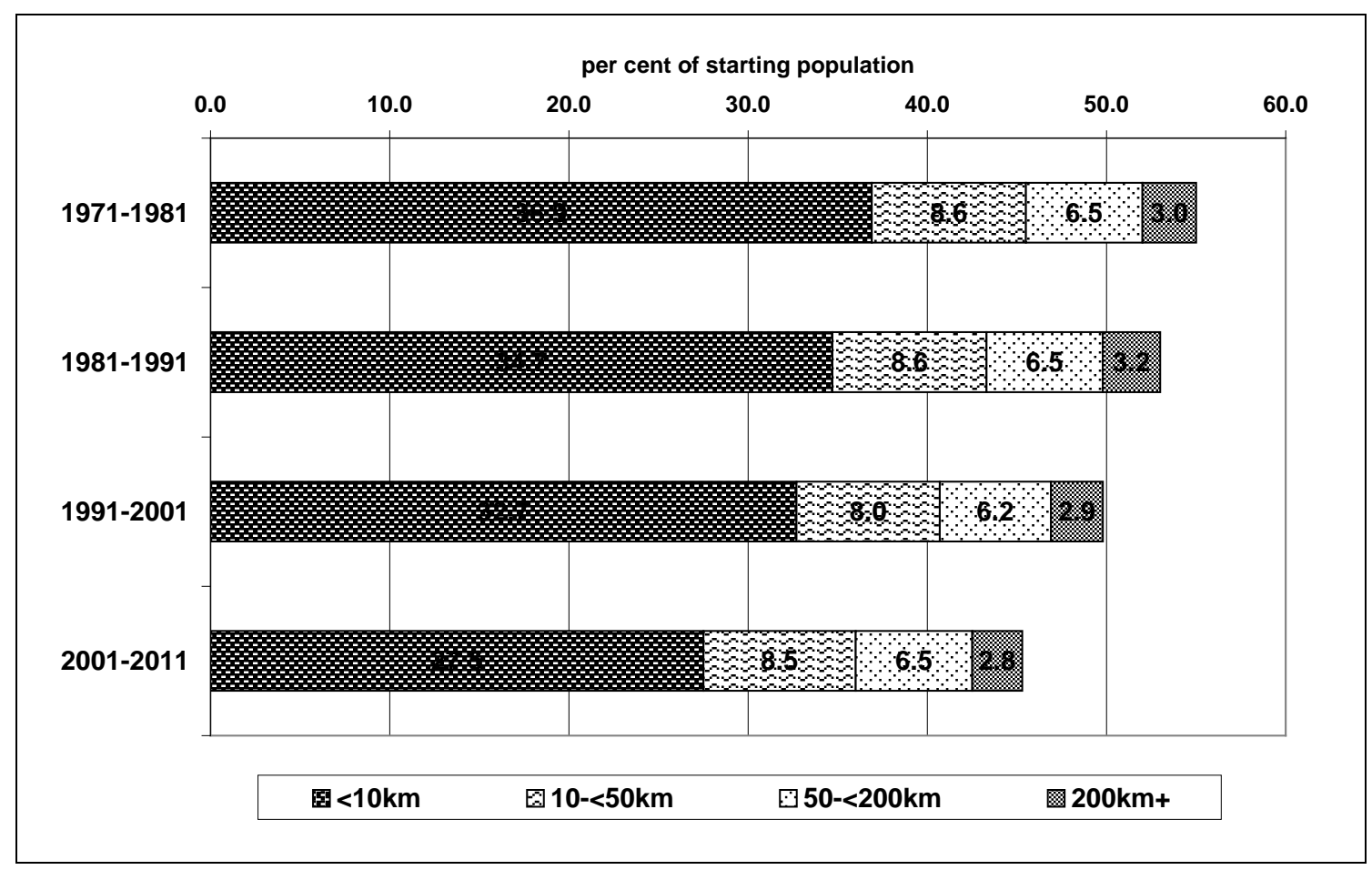


Figure 2. Proportion of all people with a different address at the end of the decade from the start, by age group (Source: calculated from ONS-LS. Crown copyright.)

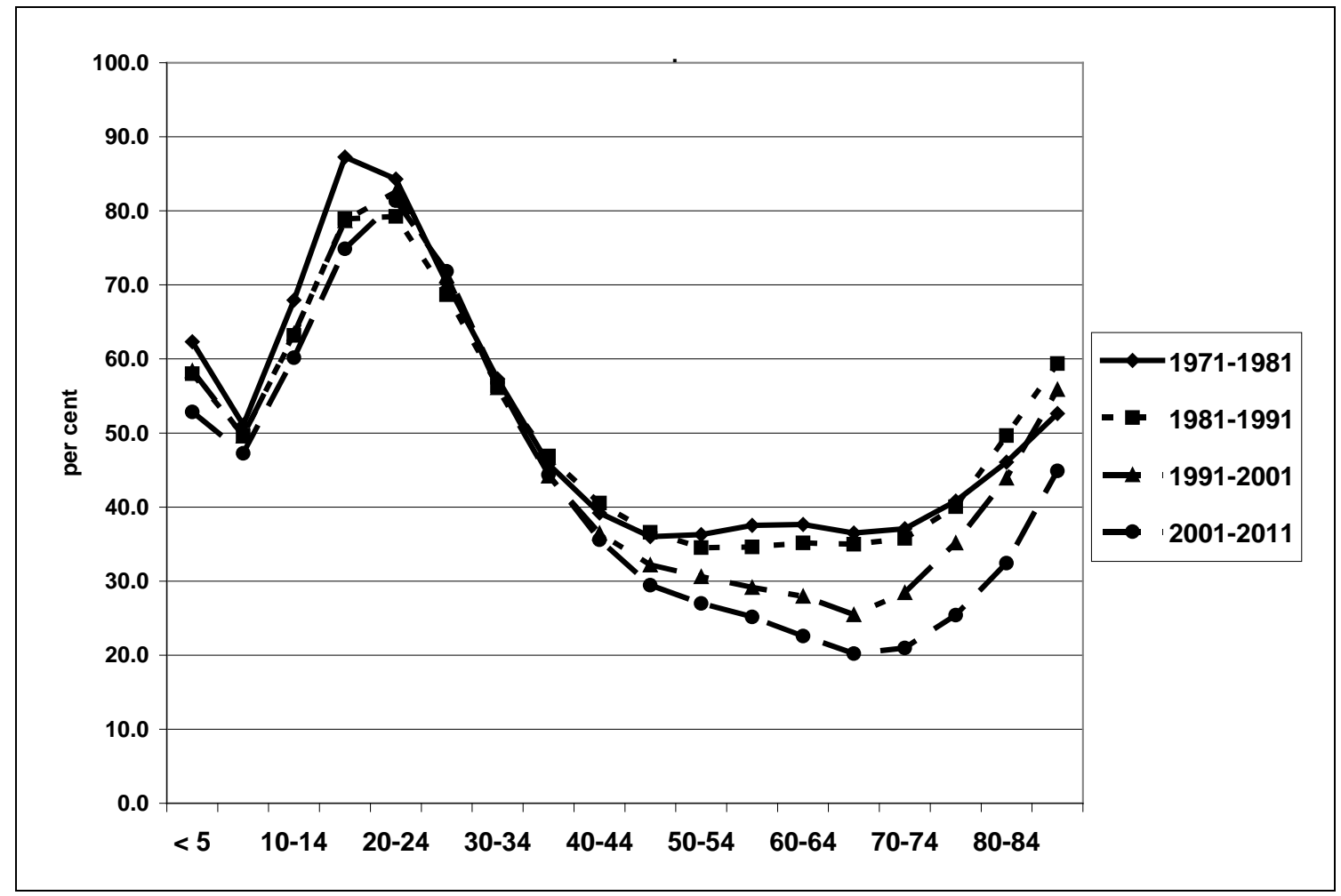

Figure 3. Proportion of all people with an address at the end of the decade at least $50 \mathrm{~km}$ away from that at the start, by Social Class (Source: calculated from ONS-LS. Crown copyright.)

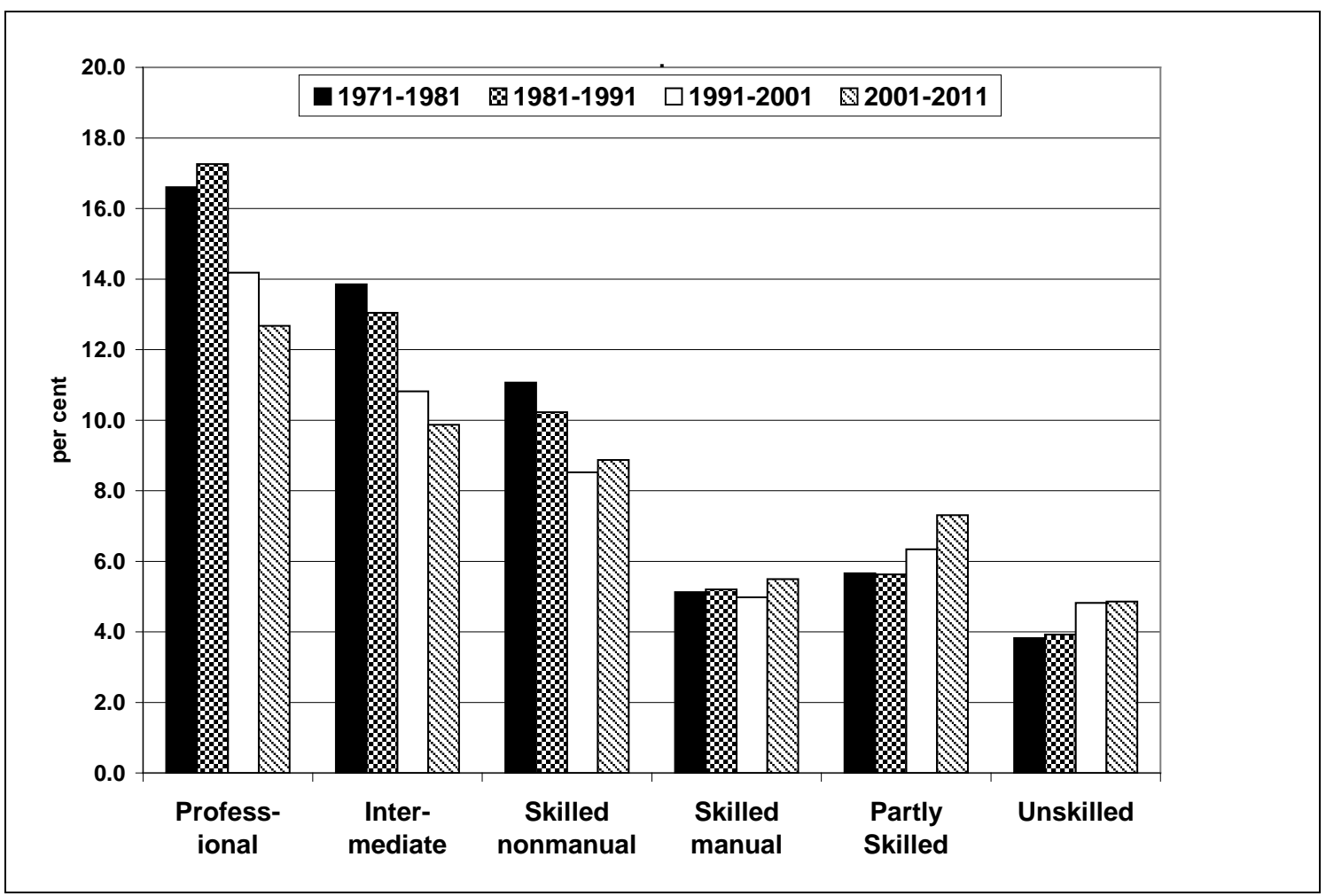

